Research paper

\title{
Implementation and evaluation of a 'Navigator' role to improve emergency department throughput
}

\author{
Paul Fulbrook $^{\mathrm{a}, \mathrm{b}, *}$, Melanie Jessup ${ }^{\mathrm{a}, \mathrm{b}}$, Frances Kinnear ${ }^{\mathrm{c}}$ \\ a School of Nursing, Midwifery and Paramedicine, Australian Catholic University, Brisbane, Australia \\ b Nursing Research and Practice Development Centre, The Prince Charles Hospital, Brisbane, Australia \\ ${ }^{c}$ Department of Emergency Medicine, The Prince Charles Hospital, Brisbane, Australia
}

\section{A R T I C L E I N F O}

\section{Article history:}

Received 6 December 2016

Received in revised form 19 May 2017

Accepted 19 May 2017

\section{Keywords:}

Emergency department

Evaluation

Nurse navigator

Patient flow

\begin{abstract}
A B S T R A C T
Background: Emergency department overcrowding impacts patients, staff, and quality of care, and there is government pressure to optimize throughput and reduce waiting times. One solution for improving patient flow is the emerging 'navigator' role: a nurse that supports staff in care delivery; facilitating efficient and timely patient movement through the emergency department.

Methods: A 20-week project was implemented to evaluate an emergency department nurse navigator role. A controlled trial was used. The navigator worked on a week-on-week-off basis, eight hours per day, seven days per week. Time-based and cost-associated outcomes were compared.

Results: Data from nearly 20,000 presentations during the trial period were analysed. All outcomes were improved during the ten weeks the Navigator was working. A slight improvement in National Emergency Access Target compliance was shown, with an average of $4.5 \mathrm{~min}$ per presentation saved. The labour cost associated with the time saved was estimated to be $\$ 170,000$.

Conclusions: The results from this study indicate that for a relatively small investment, complementary nursing roles such as the navigator can impact emergency department patient flow. However, further studies are required to determine optimisation of the role.

Relevance to practice: This study provides rigorous evidence of the effects of a nurse navigator role on emergency department throughput. Whilst positive outcomes were demonstrated, suggesting a wholeof-system benefit, the magnitude of effect on a per-presentation basis was relatively small. Further studies are required to demonstrate the clinical relevance of such roles.

(C) 2017 The Author(s). Published by Elsevier Ltd on behalf of College of Emergency Nursing Australasia. This is an open access article under the CC BY-NC-ND license (http://creativecommons.org/ licenses/by-nc-nd/4.0/).
\end{abstract}

\section{Introduction}

The cost of Australian acute healthcare is approximately $\$ 8$ billion each year, rising annually well over the inflation rate, making government health budgets potentially unaffordable within 20 years [1]. A major issue for the health system is increasing demand and overcrowding of emergency departments (ED) [2], leading to access block (when patients in ED that require admission to hospital have a total ED time greater than $8 \mathrm{~h}$ ) [3], congesting not only the ED but overall system operation, and impacting on patients and staff $[4,5]$. In this context, public health services are undergoing considerable change including reshaping their models of care

* Corresponding author at: Nursing Research and Practice Development Centre, Level 5, Clinical Sciences Building, The Prince Charles Hospital, Rode Road, Chermside, Queensland 4032, Australia.

E-mail addresses: paul.fulbrook@acu.edu.au, paul.fulbrook@health.qld.gov.au (P. Fulbrook). delivery and, in some cases, redesigning or redesignating existing services and building new facilities.

One area that has received a sharp focus from government, in terms of its effectiveness and efficiency, is the ED, which has been criticised because of escalating costs and ineffective management of throughput, resulting in long delays in admission to ED and long waiting times for patients. Furthermore, temporary closures at times of high demand, often referred to as ambulance bypass, have resulted in patients being to be transferred to other facilities for emergency treatment. However, in Queensland this is no longer allowed [6]. This means that when an ambulance arrives at an ED that is at capacity, there is usually a delay in offload from the ambulance trolley to an ED treatment area. This is referred to as ambulance ramping $[7,8]$.

In Queensland, the demand for emergency services has been compounded by the relatively rapid population growth, particularly in the south east corner. At the time of this study there was mounting pressure from the federal government's National Emer- 
gency Access Target (NEAT) to improve throughput in ED; with a target set for December 2015 to achieve ED discharge within $4 \mathrm{~h}$ for $90 \%$ of ED presentations [9]. At a Queensland state level, the government's Blueprint for Better Healthcare in Queensland [10] outlines structural and cultural improvements, including reiteration of the Metropolitan Emergency Department Access Initiative that aims to improve patient access to ED. At a local level, The Prince Charles Hospital (TPCH) Emergency Medical Services (EMS) - the setting for this study - continues to expand rapidly, having transitioned to co-located adult and paediatric services. Presentations have increased in absolute numbers from less than 13,000 in 2006 to 72,400 (adult and paediatric) at the time of this study in 2014 , and with respect to case mix and complexity.

Hospital and ED overcrowding is recognised as an increasing problem [11] that results in adverse effects upon patients and staff alike [12-14], and upon the quality of care delivered [15-18]. ED crowding has been linked to staff stress [5], decreased staff satisfaction and retention [12], prolonged inpatient length of stay (LOS) $[12,13]$ and financial implications [19,20]. Access block has been linked to increases in ED and hospital LOS, ambulance diversion, morbidity and mortality [4,5,12]. Many factors attributed to ED bed-block are hospital- or district-wide issues outside ED staff's control. However, addressing these issues with innovative strategies can facilitate whole-system flow.

When considering whole-system flow within a health district, there are several variables that impact on ED patient flow. Primarily, flow can be considered in terms of supply and demand. The latter is mainly dependent on the number of people presenting to ED as 'walk-ins' or via ambulance, whereas the former is dependent on the size of the ED and what capacity it is operating at, as well as onward availability of hospital beds. ED congestion is a function of many factors: both internal and external [21], which may be explained further using the Input-Throughput-Output model developed by Asplin et al. [22]. Input factors relate to demand, whereas throughput factors are related ED and hospital provision of care processes e.g. diagnostic services, staffing; and output factors are related to post-ED ongoing care of the patient e.g. hospital admission, transport services. Furthermore, all factors are subject to other extraneous factors such as fluxes in local population e.g. major events, seasonal variation, and policy changes [21].

Whilst it is difficult to control the number of ED walk-in or ambulance presentations, it may be possible to improve the flow of presentations by attending to the needs of patients presenting to ED in a timely manner. One way that this has been addressed is via the emerging role of the ED Navigator, a nurse that monitors and facilitates patient movement through the department by supporting staff in their delivery of care, and facilitating the patient's journey throughout the ED to ensure that it is as efficient and timely as possible. Introduction of a 24-h Navigator role was attributed with being one of several initiatives in Western Australian Health's successful attainment of NEAT targets in its Four Hour Rule Program, reportedly improving their performance by "about $15 \%$ overnight" through their monitoring of the timeline of every patient and avoiding time wastage by encouraging timely bookings, referrals, decision making and transfer/discharge of patients [23]. However, 'navigator' was a collective term applied to several different roles, such as ED Operations Manager and ED Patient Flow Coordinator that were developed independently at each hospital [24]. Unfortunately, an independent review of the Four Hour Rule Program found that the role caused stress within the ED environment, including allegations of bullying behavior. It was recommended that the role be re-examined and clearly defined [24]. In Queensland, a role similar to the Navigator, in that it aims to improve patient flow, has been implemented in some EDs: the Clinical Initiatives Nurse (CIN) [25]; the stated primary purpose of which is to improve Patient Off Stretcher Time (POST), patient flow through ED, handover processes, and to provide care to patients in the ED waiting room when required [26]. While the CIN role is purported to have achieved timely intervention and a reduction in did-not-wait rates [27], the position does vary in role description and execution [28], with little evidence regarding associated outcomes [29], albeit some anecdotal evidence suggesting that the position has assisted in the reduction of wait times [28]. A key characteristic is that the CIN is generally assigned to the front end of the department, initiating treatment before patients are seen by medical staff [29].

The navigator role requires an experienced ED nurse who is cognisant of ED processes. Navigators contribute actively to the movement of patients through the department by monitoring patient timelines and flagging a patient who is approaching their time limit for each stage or who appears to have stalled in the process, and helping to identify and troubleshoot in crisis areas. They undertake a diversity of time-consuming tasks such as coordinating bookings and patient transfers to available beds (from triage to $\mathrm{ED} /$ from ED to inpatient areas), tracking down information for those patients whose status was unclear in the admission process, and facilitating referrals and requisite decision-making. By acting as an assistant in this manner they promote the movement of patients through the department while allowing the team leaders to focus on the overall directing of flow. While various government reports are available, they tend to detail implementation of the role without supportive evidence and in the absence of valid controls. This lack of peer-reviewed research studies evaluating the navigator role highlights a gap in current knowledge and the need to gather rigorous evidence regarding this emerging role.

\section{Background}

Funding was obtained for a project to implement and evaluate a nurse navigator role within a Queensland ED. In this project, the role of the Navigator was to monitor patient timelines, flagging those approaching target times or stalled processes, identify and troubleshoot crisis areas, undertake time-consuming tasks e.g. co-ordinate bookings/patient transfers, update patient information, and facilitate referrals and decision-making; thus assisting patients' movement through ED while allowing team leaders to focus on overall flow. As this was a new role, although discussions were held with the Navigators about the role intentions, no specific training was provided. It was anticipated that the role would evolve during the course of the project. This paper presents the results of time-based and cost-related outcomes associated with the project.

Aim

Within an adult ED setting, the primary aim of this study was to objectively assess the effects of a Nurse Navigator role on NEAT and other measurable time-based outcomes. The secondary aim was to estimate the labour cost of any time saved associated with the role.

\section{Methods}

\section{Design}

This study employed a controlled trial design. Ethical approval was received from the hospital research ethics committee (ref: $\mathrm{HREC} / 14 / \mathrm{QPCH} / 23$ ).

\section{Setting and sample}

The setting for this study was a major tertiary referral hospital in Brisbane, Australia. The hospital has 630 beds and provides a broad range of specialties, including co-located paediatric and adult 
emergency services. The study was conducted in its adult ED, which currently manages approximately 70,000 presentations annually. At the time of the study, the department had employed nurses in the CIN role for around two years.

The duration of this project was determined by the funding available for the Navigator trial (10 weeks), which in turn determined the number of ED presentations included in the study. Thus, a priori sample size calculations were not undertaken. However, post hoc analysis on the primary outcome measure (NEAT) revealed that the study was sufficiently powered $(\alpha=.05, \beta=.82)$.

\section{Intervention}

A supernumerary ED Nurse Navigator role was implemented on a week-off-week-on basis for a 20 -week period during May-November 2014. The rationale for this approach was to reduce the potential for confounding variables such as staffing to bias the results. During intervention weeks, one Navigator worked eight hours per day, during the peak activity period of $12.30-20.30$. The Navigator role was shared between two senior Clinical Nurses (Queensland Health nursing grade 6.4). Navigators were identified by their bright pink shirts, which were labelled 'Nurse Navigator'.

\section{Data collection and analysis}

All patient- and time-based data were retrieved from the hospital's ED Information System (EDIS) for all ED patients that presented during the 20-week trial period. Cost data attributed to each patient presentation was provided by the health service district's Clinical Costing and Reporting/Health Funding and Analysis unit. Data were imported into a statistics software package (SPSS version 23) for analysis. Statistical significance was set at $p<.05$. Letters of complaint or compliment during the data collection period were also reviewed.

\section{Results}

Sample

Raw data were retrieved from EDIS for all patients that presented to the ED from 26 May to 12 October 2014. After data cleaning, 19773 presentations were analysed. The mean age of the sample was 50.3 years (SD 22.4) and the majority was female (52.7\%, $n=10421$ ). In terms of presentation numbers, the busiest day of the week was Monday $(n=3055,15.5 \%)$ and the quietest was Thursday ( $n=2626,13.3 \%)$, and $38.6 \%$ ( $n=7634)$ arrived by ambulance. Just over half of all presentations were in triage category 3 $(n=10175,51.5 \%)$.

Sample characteristics were compared between the two 10week periods on days when the Navigator was either working or not working (see Table 1). Although slightly more patients presented on days when the Navigator was on shift $(50.3 \%, n=9951)$, there were no statistically significant differences between the two cohorts. Chi square tests were used to compare differences in dichotomous categorical variables. Although ED length of stay was skewed towards shorter times, the $t$-test was used to analyse differences in continuous time-based variables, as it is robust for non-normally distributed large samples [30].

\section{Criterion-based performance indicators}

Within ED, there are two main criterion-based targets: a 4-h ED discharge target (NEAT), and a 2-h target for consultation referral for patients likely to be admitted to hospital. The Chi-square test (with Yates Continuity Correction for $2 \times 2$ tables) was used to analyse differences between weeks when the Navigator was working or not (see Table 2). When the Navigator was working, although the percentage differences were not large, statistically significantly more patients met NEAT $\left[X^{2}(1, n=19773), p=.003\right]$ and the 2 -h referral target $\left[X^{2}(1, n=8878), p=.036\right]$, although the effect sizes were small ( $p h i=.02$ and .02 , respectively). Considered in terms of relative risk reduction, the risk of NEAT not being met was increased by $5.1 \%$ when the Navigator was not working. In terms of numbers needed to treat, for every 49 ED presentations when the Navigator was working, one case of NEAT not being met would have been prevented. When access blocked presentations were excluded from the analysis, the percentage of presentations meeting NEAT improved by around $5 \%$ in both groups.

Overall, a NEAT time of less than $4 \mathrm{~h}$ was met in significantly more presentations that were discharged home (67.4\%) compared to those admitted to hospital (32.6\%) [ $X^{2}(1, n=19771), p<.001$, $p h i=-.31]$. For both groups, statistically significantly more presentations met the 4-h target on days when the Navigator was working [discharged presentations: $X^{2}(1, n=10901), p=.003$, phi=-.03; admitted presentations; $X^{2}(1, n=8870), p=0.036$, $\left.p h i=-.03\right]$.

\section{Time-based performance indicators}

Differences in time-based performance indicators were analysed using $t$-tests and are shown in Table 3. The Navigator reduced ED time intervals at all stages of the patient journey, with the exception of the time between patient readiness for discharge to actual discharge on which there was no effect.

\section{Ambulance ramping}

Of the 7634 patients that presented by ambulance, $24.8 \%$ $(n=1892)$ recorded a pre-ED wait time (ramp time) prior to handover to the Triage Nurse. The mean ramp time was 33.6 (SD 31.5) minutes and ranged from 1 to $202 \mathrm{~min}$ (IQR 11-46 min). Slightly fewer ambulance presentations were ramped on Navigator days (47.6\%, $\mathrm{n}=901)$ and mean ramp time was significantly shorter [mean difference 7.55 , SE $1.43,95 \%$ CI 4.76-10.35; $t(1876)=5.30$, $p<.001]$. However, this statistically significant difference was attributable to the category 3 presentations (see Table 4). Although the mean ramp time was over two minutes and eight minutes shorter in triage category 2 and 4 patients, respectively, these differences did not reach statistical significance. (Differences in triage categories 1 and 5 were not analysed as the groups were small: $n=2$ and 4 , respectively.)

\section{Time to treatment}

The mean time from ED presentation until the patient was seen by a treating physician was $63.4 \mathrm{~min}(\mathrm{SD} 61.9, n=19633)$. On days when the Navigator was working, the time until the patient was seen was significantly reduced by around two minutes [mean difference $2.07 \mathrm{~min}, \mathrm{SE}=.88,95 \% \mathrm{CI} .33-3.79, t(19631)=2.34, p=.02]$.

\section{Time to first referral}

A total of 8878 presentations were referred to other specialists or services prior to their ED discharge. Although a significant number of presentations were referred to more than one specialist/service, the time between ED arrival and the time of the first referral was used to standardise comparisons. The mean duration from arrival to first referral was $119.0 \mathrm{~min}$ (SD 98.5, IQR 46-167, $n=8878$ ). Time to first referral was significantly less on days when the Navigator was working compared to other days [mean difference $5.06 \mathrm{~min}$, SE 2.09, 95\% CI .96-9.16; $t(8876)=2.42, p=.016]$. Of this group, $64.8 \%(n=5756)$ was admitted to hospital, with a significantly shorter time to first referral in the Navigator group 
Table 1

Sample characteristics.

\begin{tabular}{|c|c|c|c|c|c|}
\hline \multirow[t]{2}{*}{ Sample characteristics } & \multirow[b]{2}{*}{ Off } & \multicolumn{3}{|c|}{ Navigator days } & \multirow{2}{*}{$\begin{array}{l}\text { Significance } \\
p\end{array}$} \\
\hline & & On & Total & & \\
\hline $\begin{array}{l}\text { Total } \\
n(\%) \\
\text { Mean age (SD) }\end{array}$ & & $\begin{array}{l}9822(49.7) \\
(100) \\
50.5(22.5)\end{array}$ & $\begin{array}{l}9951(50.3) \\
(100) \\
50.0(22.4)\end{array}$ & $\begin{array}{l}19773(100 \%) \\
(100 \%) \\
50.3(22.4)\end{array}$ & .085 \\
\hline $\begin{array}{l}\text { Gender } \\
n(\%)\end{array}$ & $\begin{array}{l}\mathrm{M} \\
\mathrm{F}\end{array}$ & $\begin{array}{l}4624(49.4) \\
(47.1) \\
5198(49.9) \\
(52.9)\end{array}$ & $\begin{array}{l}4728(50.6) \\
(47.5) \\
5223(50.1) \\
(52.5)\end{array}$ & $\begin{array}{l}9352(100) \\
(47.3) \\
10421(100) \\
(52.7)\end{array}$ & .54 \\
\hline \multirow{2}{*}{$\begin{array}{l}\text { Ambulance } \\
\text { presentation } \\
n(\%)\end{array}$} & Yes & $\begin{array}{l}3761(49.3) \\
(38.3)\end{array}$ & $\begin{array}{l}3873(50.7) \\
(38.9)\end{array}$ & $\begin{array}{l}7634(100) \\
(38.6)\end{array}$ & .371 \\
\hline & No & $\begin{array}{l}6061(49.9) \\
(61.7)\end{array}$ & $\begin{array}{l}6078(50.1) \\
(61.1)\end{array}$ & $\begin{array}{l}12139(100) \\
(61.4)\end{array}$ & \\
\hline $\begin{array}{l}\text { Triage category } \\
n(\%)\end{array}$ & $\begin{array}{l}1 \\
2\end{array}$ & $\begin{array}{l}67(49.6) \\
(0.7) \\
1394(49.6) \\
(14.2) \\
5130(50.4) \\
(52.2) \\
2700(48.3) \\
(27.5) \\
531(50.0) \\
(5.4)\end{array}$ & $\begin{array}{l}68(50.4) \\
(0.7) \\
1414(50.4) \\
(14.2) \\
5045(49.6) \\
(50.7) \\
2893(51.7) \\
(29.1) \\
530(50.0) \\
(5.3)\end{array}$ & $\begin{array}{l}135(100) \\
(0.7) \\
2808(100) \\
14.2) \\
10175(100) \\
(51.5) \\
5593(100) \\
(28.3) \\
1061(100) \\
(5.4)\end{array}$ & .153 \\
\hline
\end{tabular}

Table 2

Criterion-based targets.

\begin{tabular}{|c|c|c|c|c|}
\hline \multirow{2}{*}{$\frac{\text { Target }}{\text { NEAT }}$} & & \multicolumn{2}{|c|}{ Navigator Days } & \multirow[t]{2}{*}{ Significance $p$} \\
\hline & & Off & On & \\
\hline \multirow{2}{*}{$\begin{array}{l}\text { All presentations } \\
n=19773\end{array}$} & Not met\% $(n)$ & $39.8(3914)$ & $37.8(3762)$ & .003 \\
\hline & Met\% (n) & $60.2(5908)$ & $62.2(6189)$ & \\
\hline \multirow{2}{*}{$\begin{array}{l}\text { Non-access blocked } \\
\text { presentations } \\
n=18268\end{array}$} & Not met\% $(n)$ & $34.7(3145)$ & $32.8(3026)$ & .007 \\
\hline & Met\% $(n)$ & $65.3(5908)$ & $67.2(6189)$ & \\
\hline \multirow{2}{*}{$\begin{array}{l}\text { Admitted to hospital } \\
n=8870\end{array}$} & Not met\% $(n)$ & $56.7(2468)$ & $54.5(2461)$ & .036 \\
\hline & Met\% $(n)$ & $43.3(1884)$ & $45.5(2057)$ & \\
\hline \multirow{2}{*}{$\begin{array}{l}\text { Not admitted to } \\
\text { hospital } n=10901\end{array}$} & Not met\% (n) & $26.4(1446)$ & 23.9 (1299) & .003 \\
\hline & Met\% (n) & $73.6(4024)$ & $76.1(4132)$ & \\
\hline \multirow{3}{*}{$\begin{array}{l}\text { First referral wi } \\
\text { All referred } \\
\text { presentations } \\
n=8878\end{array}$} & & & & \\
\hline & Not met\% (n) & $50.4(1897)$ & $49.6(1868)$ & .036 \\
\hline & Met\% (n) & $48.1(2460)$ & $51.9(2653)$ & \\
\hline
\end{tabular}

Table 3

Time-based performance indicators.

\begin{tabular}{|c|c|c|c|c|}
\hline \multirow[t]{2}{*}{ Time intervals (minutes) } & \multicolumn{2}{|c|}{ Navigator Mean, median, $n$} & \multirow{2}{*}{$\begin{array}{l}\text { Mean difference } \\
(95 \% \mathrm{CI})\end{array}$} & \multirow[t]{2}{*}{ Significance $p$} \\
\hline & OFF & $\mathrm{ON}$ & & \\
\hline Ambulance ramp time & $\begin{array}{l}37.19,29, \\
991\end{array}$ & $\begin{array}{l}29.63,22, \\
901\end{array}$ & $\begin{array}{l}7.65 \\
(4.89-10.41)\end{array}$ & $<0.001$ \\
\hline Arrival until seen by treating clinician & $\begin{array}{l}64.42,45.5 \\
9750\end{array}$ & $\begin{array}{l}62.36,42 \\
9883\end{array}$ & $\begin{array}{l}2.06 \\
(.33-3.79)\end{array}$ & 0.020 \\
\hline Arrival to first referral & $\begin{array}{l}121.62,109, \\
4357\end{array}$ & $\begin{array}{l}116.56,105, \\
4521\end{array}$ & $\begin{array}{l}5.06 \\
(.96-9.16)\end{array}$ & 0.016 \\
\hline Arrival to ready to depart & $\begin{array}{l}216.65,194, \\
9822\end{array}$ & $\begin{array}{l}212.11,190, \\
9951\end{array}$ & $\begin{array}{l}4.55 \\
(1.00-8.10)\end{array}$ & 0.012 \\
\hline Ready to depart to actual depart & $\begin{array}{l}30.27,1, \\
9822\end{array}$ & $\begin{array}{l}30.43,1 \\
9949\end{array}$ & $\begin{array}{l}-.16 \\
(-2.17-1.85)\end{array}$ & 0.877 \\
\hline ED length of stay & $\begin{array}{l}247.07,214, \\
9826\end{array}$ & $\begin{array}{l}242.54,210 \\
9949\end{array}$ & $\begin{array}{l}4.53 \\
(.12-8.94)\end{array}$ & 0.044 \\
\hline
\end{tabular}


Table 4

Ramp time by triage category.

\begin{tabular}{|c|c|c|c|c|}
\hline \multirow[t]{2}{*}{ Triage category } & \multicolumn{2}{|c|}{ Ramp time min Mean $(n)$} & \multicolumn{2}{|l|}{ Difference } \\
\hline & Navigator off & Navigator on & Mean difference (min), 95\% CI & Significance $p$ \\
\hline 2 & $26.70(56)$ & $24.27(66)$ & $2.42,-7.45-12.30$ & .623 \\
\hline 3 & $38.06(868)$ & $30.28(753)$ & $7.79,4.77-10.81$ & $<.001$ \\
\hline 4 & $35.26(65)$ & $28.86(78)$ & $8.40,-2.25-19.06$ & .121 \\
\hline
\end{tabular}

Table 5

ED length of stay by triage category.

\begin{tabular}{|c|c|c|c|c|c|c|}
\hline \multirow[t]{2}{*}{ Triage category } & \multicolumn{3}{|c|}{ ED length of stay (min): all presentations } & \multicolumn{3}{|c|}{ ED length of stay (min): Non-access blocked } \\
\hline & $\begin{array}{l}\text { Navigator Off } \\
(\mathrm{SD}, n)\end{array}$ & $\begin{array}{l}\text { Navigator On } \\
(\mathrm{SD}, n)\end{array}$ & $\begin{array}{l}\text { Significance } \\
p\end{array}$ & $\begin{array}{l}\text { Navigator Off } \\
(\mathrm{SD}, n)\end{array}$ & $\begin{array}{l}\text { Navigator On } \\
(\mathrm{SD}, n)\end{array}$ & $\begin{array}{l}\text { Significance } \\
p\end{array}$ \\
\hline 1 & $\begin{array}{l}238.4 \\
(203.2,67)\end{array}$ & $\begin{array}{l}227.5 \\
(163.7,68)\end{array}$ & .773 & $\begin{array}{l}193.3 \\
(137.1,61)\end{array}$ & $196.8(124.5,63)$ & .885 \\
\hline 2 & $\begin{array}{l}303.2 \\
(192.2,1394)\end{array}$ & $\begin{array}{l}300.3 \\
(190.0,1414)\end{array}$ & .684 & $\begin{array}{l}245.5 \\
(108.0,1203)\end{array}$ & $242.6(108.4,1225)$ & .503 \\
\hline 3 & $\begin{array}{l}264.8 \\
(157.8,5130)\end{array}$ & $\begin{array}{l}258.8 \\
(157.8,5043)\end{array}$ & .057 & $\begin{array}{l}228.8 \\
(103.9,4660)\end{array}$ & $\begin{array}{l}224.2 \\
(101.7,4618)\end{array}$ & .032 \\
\hline 4 & $\begin{array}{l}201.5 \\
(128.6,2700)\end{array}$ & $\begin{array}{l}200.9 \\
(129.5,2893)\end{array}$ & .861 & $\begin{array}{l}185.2 \\
(92.7,2601)\end{array}$ & $\begin{array}{l}184.7 \\
(93.6,2790)\end{array}$ & .851 \\
\hline 5 & $\begin{array}{l}161.8 \\
(93.6,531)\end{array}$ & $\begin{array}{l}163.5 \\
(110.2,530)\end{array}$ & .778 & $\begin{array}{l}159.9 \\
(90.5,528)\end{array}$ & $\begin{array}{l}154.3 \\
(92.3,518)\end{array}$ & .320 \\
\hline
\end{tabular}

compared to the remainder [mean difference $6.80 \mathrm{~min}$, SE 2.53, 95\%

CI 1.84-11.76; $t(5754)=2.03, p=.007]$.

Time until ready for departure

The mean time from triage presentation until the patient was ready for ED departure was 214.4 min (SD 127.3, IQR 129-265, $n=19,773$ ). On days when the Navigator was working patients were ready significantly sooner [mean difference $4.56 \mathrm{~min}, \mathrm{SE} 1.81$, $95 \%$ CI 1.00-8.10; $t(19711)=2.51, p=.012$ ]. On average, patients departed from ED half an hour after they were ready to leave (mean $30.3 \mathrm{~min}, \mathrm{SD} 72.2, n=19,771)$. There was no significant difference on days the Navigator was working.

\section{ED length of stay}

The mean ED length of stay was 244.8 min (SD 158.2, IQR 141-306, $n=19771)$. ED LOS was significantly shorter on days that the Navigator was working [mean difference $4.53 \mathrm{~min}$, SE 2.25 , 95\% CI .12-8.94; $t(19769)=2.01, p=.044]$. However, 1503 (7.6\%) presentations were access blocked i.e. their ED length of stay was greater than eight hours. With this group excluded, mean ED length of stay was $212.4 \mathrm{~min}$ (SD 103.5, IQR 136-275). When access blocked presentations were excluded, this difference fell to $3.67 \mathrm{~min}$ but was statistically more significant $[t(18266)=2.40$, $p=.017]$.

Further analysis of time-based indicators according to triage category revealed that ED length of stay was shorter in all triage categories, except category 5, on days when the Navigator worked. In the largest category (category $3, n=9728$ ) the difference approached statistical significance $(p=.057)$. However, when access blocked presentations were excluded from the analysis, the 4.59 min difference (SE 2.16, 95\% CI .40-8.77) found in category 3 was statistically significant $[t(9276)=2.15, p=.032]$. See Table 5 .

\section{Quality indicators}

Although this study did not set out to investigate patient satisfaction, as it is unlikely that patients would have been aware of the Navigator role, complaints and compliments received during the study were reviewed. Of the total number of complaints received
Table 6

Complaints and compliments.

\begin{tabular}{lll}
\hline & Navigator off & Navigator on \\
\hline Total complaints & $51(62.2 \%)$ & $31(37.8 \%)$ \\
Access complaints & $11(78.6 \%)$ & $3(21.4 \%)$ \\
Communication complaints & $7(50 \%)$ & $7(50 \%)$ \\
Compliments & $24(55.8 \%)$ & $19(44.2 \%)$ \\
\hline
\end{tabular}

( $n=82$ ), two thirds related to patient presentations when the Navigator was not working. There were 14 complaints about access but less than a quarter of these related to patient presentations on days when the Navigator was working (see Table 6). Slightly more compliments were received relating to presentations when the Navigator was not working.

\section{Cost-benefit analysis}

A simple cost-benefit analysis was undertaken. In ED, the cost of each presentation is calculated based on a matrix of three factors: i) ED triage category; ii) primary diagnosis, and iii) whether the patient was admitted to hospital or not; which comprise the Urgency Related Group (URG). Over the 20 weeks of the project, 19717 presentations were categorised to 115 different URGs. The largest group was URG 58 (triage category 4; injury presentation; not admitted; $n=1926 ; 9.8 \%$ ). The top 10 URGs are shown in Table 7. The Mann-Whitney $U$ test was used to examine differences between the number of presentations by URG when the Navigator was working or not. No statistically significant difference was found $(p=.77)$.

Seven eight-hour shifts per week, from Monday to Sunday, at clinical nurse grade 6.4 [2014 Queensland Health fortnight (76 h) rate $=\$ 3,326.90=\$ 43.775 /$ hour] were costed for the 10 weeks when the Navigator was working. This was the only direct financial cost that was incurred. The cost of the Navigator was calculated as follows:

Cost $=[(5 \times 8-\mathrm{h}$ days $($ Mon-Fri $)=40 \mathrm{~h}=\$ 1751)+(1 \times 8-\mathrm{h}$ day plus $50 \%$ penalty rate (Saturday) $=8 \times 1.5 \mathrm{~h}=12 \mathrm{~h}=\$ 525.30$ ) $+(1 \times 8$-h day plus $75 \%$ penalty rate (Sunday) $=8 \times 1.75 \mathrm{~h}=14 \mathrm{~h}$ $=\$ 612.85)] \times 10$ (weeks) $\times 1.3(30 \%$ standard on-costs $)=\$ 37,559$.

Based on the actual labour costs attributed to each patient episode, a dollar cost per ED minute was calculated for each pre- 
Table 7

Top 10 URGs.

\begin{tabular}{|c|c|c|c|c|c|c|}
\hline URG & $\begin{array}{l}\text { Triage } \\
\text { category }\end{array}$ & $\begin{array}{l}\text { Presenting } \\
\text { diagnosis }\end{array}$ & $\begin{array}{l}\text { Admitted to } \\
\text { hospital }\end{array}$ & $\begin{array}{l}\text { Average labour } \\
\text { cost per minute } \\
\text { (AUD) }\end{array}$ & $\begin{array}{l}\text { Total number of } \\
\text { presentations } \\
\text { (Navigator } \\
\text { off/on) }\end{array}$ & $\begin{array}{l}\text { Percentage of } \\
\text { total sample } \\
\text { (cumulative } \\
\text { percentage) }\end{array}$ \\
\hline 58 & 4 & Injury & No & $\$ 4.48$ & $1926(931 / 995)$ & $9.8(9.8)$ \\
\hline 24 & 3 & Circulatory system, endocrine, nutritional, metabolic illness & Yes & $\$ 2.08$ & $1349(658 / 691)$ & $6.8(16.6)$ \\
\hline 16 & 2 & Circulatory system, endocrine, nutritional, metabolic illness & Yes & $\$ 4.04$ & $1105(548 / 557)$ & $5.6(22.2)$ \\
\hline 23 & 3 & Digestive system illness & Yes & $\$ 2.78$ & $1031(512 / 519)$ & $5.2(27.4)$ \\
\hline 50 & 3 & Injury & No & $\$ 4.30$ & $956(475 / 481)$ & $4.8(32.3)$ \\
\hline 73 & & Did not wait & No & $\$ 18.79$ & $796(402 / 394)$ & $4.0(36.3)$ \\
\hline 27 & 3 & Respiratory system illness & Yes & $\$ 2.39$ & $769(385 / 384)$ & $3.9(40.2)$ \\
\hline 48 & 3 & Circulatory system, endocrine, nutritional, metabolic illness & No & $\$ 2.71$ & $754(380 / 374)$ & $3.8(44.1)$ \\
\hline 52 & 3 & Gastrointestinal/digestive system illness & No & $\$ 3.00$ & $633(357 / 276)$ & $3.2(47.3)$ \\
\hline 20 & 3 & Injury & Yes & $\$ 2.81$ & $598(298 / 300)$ & $3.0(50.3)$ \\
\hline
\end{tabular}

sentation. The cost per minute was multiplied by the average time saved per presentation ( $4.53 \mathrm{~min}$ ) during the weeks when the Navigator was working. Based on an average saving of $4.53 \mathrm{~min}$ per patient on Navigator weeks $(n=9917)$ the estimated cost of the saved labour time was $\$ 211,783$. Subtracting the cost to employ the Navigator, the resultant saved labour time cost over the 10 weeks was estimated at $\$ 174,224$. By applying the same logic to the presentations during the weeks when the Navigator was not working ( $n=9796)$, if the Navigator had been working, and had saved an average of 4.53 min per patient, then a further $\$ 160,282$ in labourtime costs could have been saved. Again, subtracting the cost of employing the Navigator, the potential labour cost for the 10 weeks is estimated to be $\$ 122,723$. Thus, if a Navigator had been employed for the duration of the 20-week project, the cost attributable to labour time saved is estimated to be $\$ 296,947$, which equates to $\$ 14,847$ per week or $\$ 2121$ per day.

\section{Discussion}

Although there are some reports in the literature of similar ED roles to the Navigator investigated in this study, we have found no other studies that have attempted to measure their effect. This study has produced statistically significant reductions in ED patient journey times. However, interpretation of statistical significance should be treated cautiously since large samples, such as that used in this study, will almost always demonstrate statistically significant differences [31] therefore the difference between the two group means (absolute effect size) should be considered carefully in terms of its clinical importance. In this study, an absolute effect of $4.5 \mathrm{~min}$ was achieved. Whilst the average time-saved per presentation was relatively small, it is argued that its clinical significance is in its multiplication across thousands of presentations, as an indicator of overall improved efficiency.

Several other factors should be considered when interpreting the results of this study. First, is the length of time $(8 \mathrm{~h})$ of the Navigator shift. If the hours were to be increased - perhaps to $16 \mathrm{~h}$ or more - then the time-saving effect would very likely be magnified. Further research is needed to establish the number of Navigator hours, and at what time(s) of day, time-saving benefit would be optimised. In this study, in terms of time-saved, it is clear that the Navigator had greatest effect on the early stages of the patient ED journey, including reduction in the number of ramped cases and the ramp wait time. However, at each end of the Navigator's shift there were some presentations that were unlikely to have been directly affected to any great extent i.e. those whose presentation occurred prior to the shift commencing and were in the latter half of their ED journey, and those at the end of the shift that were at the start of their ED journey. Overall, however, it is contended that there would have been some degree of forward flow effect as a result of the Navigator's activity; but this is very difficult to estimate.
Second, is the high turnover of the ED. In the department in which the study was undertaken there were 55,788 presentations in 2015. The average labour cost per minute, for all presentations during this study, was $\$ 4.17$ per minute. If an average 4.53 min was saved per presentation, it would represent a total labour cost of just over one million dollars over the course of a year. Of course, the cost of employing a navigator seven days per week would need to be subtracted. Thus, at 2015 rates, if a Navigator was employed $8 \mathrm{~h}$ per day for the whole of 2015 (cost $\$ 154,426$ ), the equivalent of around $\$ 900,000$ in labour cost may have been saved.

Third, is the effect of the individual nurses in the Navigator role. In this study, two senior clinical nurses shared the role. Each had a uniquely different personality and approached the role somewhat differently. In particular, the way they engaged with members of the multidisciplinary team would have had an influential effect on the processes they were trying to influence. Equally, there were some staff - mostly nurses - that were not fully supportive of the role and were resistant to attempts by the Navigator to help improve throughput. In part, this may be attributed to individual personalities, although it is evident from our qualitative findings that some staff felt their chain of command was being challenged and others felt somewhat harassed or criticised for underperforming [32]. In an already time-pressured environment, managing interpersonal relationships can be challenging, however clinical concerns should always take precedence and this, along with the preservation of the usual chain of command, should help to alleviate feelings of harassment or even bullying as has been reported anecdotally in some departments where patientflow roles have been introduced [23]. Roles such as the Navigator work best when relationships are perceived as collaborative and provide assistance to improve system flow, rather than using a punitive approach.

The primary purpose of the Navigator role is to enhance ED throughput, thus impacting on NEAT times. In this study, although ED length of stay was shortened when the Navigator was working, the overall impact on NEAT performance was only marginal, and it is estimated that only one more patient per every 49 presentations met the 4-h NEAT time when the Navigator was working. This may in part be due to the influence of hospital occupancy on ED throughput. Our data suggest that the Navigator impacts patient flow most at the early stage of the patient's journey, with the effect reducing as ED length of stay increases. Forward flow through the ED may be affected by external factors, such as hospital bed occupancy, even though the patient may be ready for discharge, and it is argued that better hospital bed management is needed [33]. For example, in a Canadian study, ED LOS was reported to increase extensively when hospital occupancy exceeded a $90 \%$ threshold [34]. An Australian study of access blocked ED patients suggests that the relationship may be reciprocal [5]. In this retrospective cohort study, access-blocked patients were found to 
have a significantly longer hospital length of stay. However, further work is needed for such comparisons using matched controls. In Queensland, Australia, a relatively recent study investigated the relationship between NEAT and access block [35]. In their 5-year retrospective analysis of 30 EDs it was found that although NEAT and access block were positively correlated, the relationship was complex, with access block peaks and NEAT non-compliance peaks occurring at different times. Furthermore, the variance was significantly different for admitted and non-admitted patients, and NEAT non-compliance was more strongly associated with larger hospitals.

In this study, NEAT compliance rates for patients admitted to hospital and those not admitted was found to be $32.6 \%$ and $67.4 \%$, respectively, which are similar to those reported in a recent 4 -year national retrospective study of NEAT times [36]. In that study, it was concluded that there was no mortality benefit associated with increasing total and admitted NEAT compliance above $83 \%$ and $65 \%$, respectively. The ideal NEAT compliance rate would optimally decongest EDs whilst minimising the potential harm to patients by rushed or suboptimal treatment [36]. In our study, the focus of the Navigator role was more on initiating actions, or restarting stalled actions, as opposed to encouraging staff to perform activities more quickly. Rather than harming the patient, this focus reduces the potential for suboptimal care by helping to ensure it is managed in a timely manner.

\section{Limitations}

There are several limitations to this study. First, the accuracy of the data entered into EDIS is subject to human error and cannot be validated; however the magnitude of the dataset and the week-onweek-off implementation of the Navigator role will have helped to ensure that any data entry errors were equally distributed. Second, as noted above, the effectiveness of the Navigator role is strongly influenced by the experience and personality of its incumbent. The two Navigators in this study were highly experienced ED nurses that had been working in the ED for a substantial period of time, and less experienced nurses that are not as familiar with a particular ED environment and system may have less success. Third, there are many extraneous variables in the ED setting that can influence patient flow and are outside the locus of control of the ED, for example wait times for investigations such as MRI scans. These factors were not recorded and therefore it is possible that there were other confounding variables, in either group, that may have affected outcomes.

Finally, it is important to note that labour cost can only be decreased by reducing staff hours, and it would be unrealistic to suggest doing so on the basis of this cost analysis. Another area for consideration is the potential cost-saving associated with reduced ambulance ramp times, as well as in terms of efficiencies for the ambulance service. We did not have access to ambulance service data to calculate this cost, but this is an area for future research.

\section{Conclusions}

The results from this study indicate that for a relatively small investment, complementary nursing roles such as the Navigator can impact upon ED patient flow. However, it is important to appreciate that the Navigator role is not directly associated with patient care; rather, by working with all ED staff, their impact is rippled throughout the whole department. Thus, when time-saving is considered on an average per patient basis it reflects a whole of system benefit. Further studies are required to determine optimisation of the navigator role.

\section{Provenance and conflicts of interest}

This paper was not commissioned and there are no conflicts of interest.

\section{Funding}

This project was funded by a grant from The Australian Centre for Health Services Innovation. Grant number SG0015-000494. The funding body had no role in the conduct of the study or preparation of the article for publication.

\section{Acknowledgements}

The research team would like to acknowledge the two Navigators that participated in this study and to thank the ED staff for their support.

\section{References}

[1] Australian Health Care Reform Alliance. Strengthening primary health care and prevention as the core of the health system; 2015 (Accessed December 2016) Available from: http://www.healthreform.org.au/ahcra-priorities/.

[2] Australian Institute of Health and Welfare Australian Hospital Statistics 2011-12. Health services series 50. Cat. no. HSE 134. Canberra: AIHW; 2013.

[3] Australian College of Emergency Medicine. Australian College of Emergency Medicine policy document standard terminology. Emerg Med 2002;14(3):337-40

[4] Brown DFM. Marked increase in patients who leave the ED without treatment: a troubling byproduct of some new ED divert policies. Acad Emerg Med 2002;9(5):510

[5] Richardson DB. Increase in patient mortality at 10 days associated with emergency department overcrowding. Med J Aust 2006;184(5):213-6.

[6] Springborg L. Minister for health sets new direction for access to emergency treatment. Queensland Government; 2012 (Accessed December 2016). Available from: http://statements.qld.gov.au/Statement/Id/80037.

[7] Hammond E, Shaban RZ, Holzhauser K, Crilly JL, Melton N, FitzGerald GJ, et al. An exploratory study to examine the phenomenon and practice of ambulance ramping at hospitals within the Queensland Health Southern Districts and the Queensland Ambulance Service. Griffith University \& Queensland Government; 2011.

[8] Metropolitan Emergency Department Access Initiative, A report on ambulance ramping in metropolitan hospitals. Queensland Government; 2012 (Accessed March 2017). Available from: https://www.health.qld.gov.au/ _data/assets/pdf_file/0026/434906/final_medai_report.pdf.

[9] Australian Government. National health reform. In: expert panel review of elective surgery and emergency access targets under the National Partnership Agreement on Improving Public Hospital Services. Report to the Council of Australian Governments; 2017 (Accessed December 2016) Available at: https://www.coag.gov.au/node/44.

[10] Queensland Government. Blueprint for better healthcare in Queensland. Brisbane: State of Queensland (Queensland Health); 2013.

[11] Richardson D, Kelly AM, Kerr D. Prevalence of access block in Australia 2004-2008. Emerg Med Australas 2009;21(6):472-8.

[12] Fatovich DM, Nagree Y. Access block causes emergency department overcrowding and ambulance diversions in Perth: Western Australia. Emerg Med J 2005;22(5):351-4

[13] Finefrock SC. Designing and building a new emergency department: the experience of one chest pain, stroke, and trauma center in Columbus, Ohio. J Emerg Nurs 2006;32(2):144-8

[14] Singer AJ, Thode HC, Viccellio P, Pines JM. The association between length of emergency department boarding and mortality. Acad Emerg Med 2011;18(12):1324-9.

[15] Bernstein SL, Aronsky D, Duseja R, Epstein S, Handel D, Hwang U, et al. The effect of emergency department crowding on clinically oriented outcomes. Acad Emerg Med 2009;16(1):1-10.

[16] Collis J. Adverse effects of overcrowding on patient experience and care. Emerg Nurse 2010;18(8):34-9.

[17] Keegan AD. Hospital bed occupancy: more than queuing for a bed. Med J Aust 2010;193(5):291-3.

[18] Helm JE, AhmadBeygi S, Van Oyen MP. Design and analysis of hospital admission control for operational effectiveness. Prod Operat Manage 2011;20(3):359-74

[19] Handel DA, Hilton JA, Ward MJ, Rabin E, Zwemer FL, Pines JM. Emergency department throughput, crowding, and financial outcomes for hospitals. Acad Emerg Med 2010;17(8):840-7.

[20] Pines JM, Batt RJ, Hilton JA, Terwiesch C. The financial consequences of lost demand and reducing boarding in hospital emergency departments. Annals Emerg Med 2011;58(4):331-40. 
[21] Toloo S, Fitzgerald G, Aitken P, Ting J, Tippett V, Chu K. Emergency health services: demand and service delivery models. Monograph 1: literature review and activity trends. Brisbane: Queensland University of Technology; 2011.

[22] Asplin BR, Magid DJ, Rhodes KV, Solberg LI, Lurie N, Camargo CA. A conceptual model of emergency department crowding. Ann Emerg Med 2003;42(2):173-80.

[23] Monaghan M. QA with Mark Monaghan. NSW: Emergency Care Institute; 2012 (Accessed December 2016). Available from http://www.ecinsw.com.au/ mark-monaghan.

[24] Stokes B. Four Hour Rule Program: progress and issues review. Perth: Department of Health WA; 2011.

[25] Queensland Government. Guidelines for the implementation of the clinical initiatives nurse (CIN) role in. State of Queensland (Queensland Health); 2012.

[26] NSW Department of Health. The clinical initiatives nurse role in emergency departments. Sydney: NSW Department of Health; 2010.

[27] Fry M, Jones K. The clinical initiative nurse: extending the role of the emergency nurse, who benefits? Australas Emerg Nurs J 2005;8(1-2):9-12.

[28] Cashin A, O'Connell J, Christofis L, Lentakis A, Rossi M, Crellin D. Clinical initiative nurses and nurse practitioners in the emergency department: what's in a name? Australas Emerg Nurs J 2007;10(2), 73-70.

[29] Schofield D. Literature review of emergency department staffing redesign framework. Lismore, NSW: Northern Rivers University of Department of
Health; 2011 (Accessed December 2016). Available at: http://www.health. nsw.gov.au/workforce/Documents/literature-review-emergencydepartment-staffing.pdf.

[30] Fagerland MW. T-tests, non-parametric tests, and large studies -a paradox of statistical practice? BMC Med Res Method 2012;12:78.

[31] Sullivan GM, Feinn R. Using effect size - or why the $P$ value is not enough. J Grad Med Educ 2012;4(3):279-82.

[32] Jessup M, Fulbrook P, Kinnear K. Staff evaluation of the role of an emergency department nurse navigator. In: 4th International Conference for Emergency Nurses. 2016.

[33] Proudlove NC, Gordon K, Boaden R. Can good bed management solve the overcrowding in accident and emergency departments? Emerg Med J 2016;20(2):149-55.

[34] Forster AJ, Stiell I, Wells G, Lee AJ, Van Walraven C. The effect of hospital occupancy on emergency department length of stay and patient disposition. Acad Emerg Med 2003;10(2):127-33.

[35] Khanna S, Boyle J, Good N, Lind J. New emergency department quality measure: from access block to National Emergency Access Target compliance. Emerg Med Australas 2013;25(6):565-72.

[36] Sullivan C, Staib A, Khanna S, Good NM, Boyle J, Cattell R, et al. The National Emergency Access Target (NEAT) and the 4-hour rule: time to review the target. Med J Aust 2016;204(9):354, e1-354. e. 